\title{
La industria manufacturera mexicana vista en el contexto de industrialización de China e India
}

Mexican manufacturing seen in the context of industrialization of China and India

\section{Resumen}

El artículo analiza cómo el desarrollo industrial alcanzado en países desarrollados, se logró a través de la intervención directa del Estado en la economía, y ha sido el proceso de liberalización económica lo que está desindustrializando a muchos de ellos. Se han originado cambios significativos en la estructura económica a nivel mundial, llevando a que la industria se ubique en China y en otros países del sudeste asiático, y un acelerado proceso de financiarización de la mayoría de las economías. El trabajo analiza las características de la industrialización en China e India, así como la desindustrialización en México y el impacto que ello ha ocasionado sobre el diferencial de crecimiento entre ellos. Al final se analiza el desafio que enfrentan los países latinoamericanos ante la desaceleración de la economía mundial que cuestiona la estrategia de crecimiento hacia fuera, por lo que se plantea la necesidad de retomar el crecimiento hacia adentro, con la mayor participación del Estado en la economía.

Palabras clave:

- Orden económico internacional

- Política Comercial

- Integración económica
Arturo Huerta González*

\section{Abstract}

The paper analysis how the industrialization process was due the intervention of the State in the economy, and how the economic liberalization has de-industrialized the economies. Important changes in the economic structure in the world have occured in favor of the financierization process. The industrial sector has gone to China and to SudEast Asian countries. The paper analyses the industrialization in China and India, and the de-industrialization in Mexico, and its impact in the economic growth. At the end, the present stagnation process is analysed and how it impacts to Latin American countries that question the export gowth estrategy and it is presented a proposal of internal market growth strategy with a State participation.

\section{Los países se industrializaron gracias a políticas de intervención del Estado}

Ante los efectos recesivos que ocasionó la Gran Depresión de 1929-1933 en los países de América Latina, llevó a éstos a replantear la estrategia de crecimiento del primario-exportador que venía predominando y los había colocado en una situación de alta dependencia respecto a la dinámica de los países desarrollados.

- International Economic Order

- Commercial Policy

- Economic Integration

JEL: F02, F13, F15 De ahí que se pasó a la estrategia de crecimiento hacia el mercado interno para alcanzar dinámicas más endógenas y menos vulnerables al acontecer internacional. La Segunda Guerra Mundial (II GM), impulsó el desarrollo industrial 
manufacturero en varios países del área, dado que Estados Unidos dejó de abastecer su demanda de bienes manufacturados, debido a la reconversión de su industria hacia la producción bélica. Una vez terminada la II GM, se establecieron políticas de permisos previos de importación para proteger la producción frente a importaciones, para seguir impulsando el proceso de industrialización para lograr una dinámica más sostenida.

América Latina se industrializó gracias a políticas de intervención del Estado en la economía, que manejó la política fiscal para desarrollar infraestructura, así como sectores estratégicos para apuntalar dicho sector. Instrumentó políticas de expansión del gasto público para dinamizar el mercado interno, otorgó subsidios, exenciones tributarias, así como políticas crediticias favorables del sector manufacturero.

Por su parte, los gobiernos de los países del Sudeste Asiático (PSA) promovieron industrias selectivas a través de fuertes inversiones en ciencia y tecnología, como en el desarrollo de capital humano. Establecieron sistemas de crédito dirigidos, evitaron distorsiones de precios relativos que afectaran la producción manufacturera, se abrieron a la tecnología extranjera, y procedieron a políticas comerciales de empuje a las exportaciones (Kosacoff y Ramos, 1999).

Los PSA privilegiaron una estrategia de promoción de exportaciones, a través de tipos de cambio competitivos, y políticas de apoyo crediticio, y de subsidios a su industria, las cuales eran condicionadas a metas, y de no cumplirse, las empresas eran sancionadas. El impulso al desarrollo tecnológico, y a la formación de capital humano, por parte de estos gobiernos, ha sido pieza clave permitiendo obtener grandes resultados en su industrialización, como en sus niveles de competitividad, y en su presencia en los mercados internacionales.

No ha sido el mercado el que ha desarrollado la productividad, las ventajas comparativas y competitivas que han permitido el éxito de las exportaciones, y la dinámica manufacturera de estos países, sino la acción del gobierno, con políticas expresas para alcanzar las metas fijadas. El desarrollo tecnológico, como la infraestructura, y la formación de mano de obra calificada, requieren de fuertes montos de inversión, que los gobiernos impulsaron. Sin la visión de éste, no se puede alcanzar el desarrollo industrial, y los niveles productivos y competitivos, requeridos para su desarrollo exitoso.

La evidencia empírica ha constatado que ha sido la acción directa de los gobiernos, a través de políticas industriales específicas, han conseguido impulsar y crear ventajas comparativas de sectores productivos que han pasado a tener una posición importante en el comercio internacional. 


\section{La globalización y su impacto en la desindustrialización de muchos países}

A raíz de la crisis de deuda de inicios de los años ochenta, en América Latina se dejaron de lado las políticas de intervención y regulación del Estado en la economía. Como consecuencia de las renegociaciones de la deuda con el Fondo Monetario Internacional, pasaron a privilegiarse las políticas de liberalización y desregulación económica, las que se justificaron bajo el principio de que la competencia que ello propicia, impulsa la reestructuración, la modernización y la eficiencia del aparato productivo, para alcanzar situaciones de holgura en el sector externo, para poder cubrir el pago de la deuda. Quedaron de lado las políticas industriales. Se le dio al mercado de economía abierta la tarea de la asignación de recursos, para que a través de ello se alcanzaran altos niveles de eficiencia y especialización, como el desarrollo de ventajas comparativas y competitivas, y así impulsar el desarrollo de las economías.

La libre movilidad de mercancías ha ido acompañada del libre movimiento de capitales, el cual exige políticas macroeconómicas a su favor, por lo que han predominado políticas monetarias y fiscales restrictivas y tipos de cambios apreciados, lo cual ha actuado en detrimento de la competitividad de la producción nacional, y dicha política, más que ocasionar una mejor asignación de recursos, y mayor eficiencia, ha afectado la dinámica manufacturera, incrementado las presiones sobre la balanza de comercio exterior, y frenado la actividad económica.

La liberalización comercial, y el aumento de la competencia que ello propicia, ha llevado a que las empresas transnacionales trasladen sus procesos productivos a otros países en la perspectiva de abaratar costos, y mejorar su posición competitiva, aprovechando las ventajas comparativas, competitivas y de localización que ofrecen. Se han internacionalizado los procesos productivos, ocasionando cambios en la estructura productiva en los diferentes países, como en sus niveles de industrialización.

La liberalización comercial y la relocalización de procesos productivos, ha ido acompañado de grandes flujos de Inversión Extranjera Directa (IED), a los diferentes países, y sobre todo a aquellos que pasan a ofrecer mejores ventajas para dichas empresas. Tales inversiones son las que realizan las transformaciones en la estructura productiva, y por lo tanto, determinan las características de su dinámica productiva, como de su comercio exterior. La creciente interrelación de las economías, y la diseminación de los procesos productivos, y las respectivas cadenas de producción, ha dinamizado el comercio mundial, 
originando que las economías con mayores ventajas competitivas expandan su comercio y sus mercados, y pasen a ser superavitarias y tengan gran dinamismo. En cambio, pierden aquellos países cuyas cadenas productivas e industrias son desplazadas por importaciones, debido a su falta de competitividad, por lo que se incrementa su déficit de comercio exterior, y se reducen los efectos multiplicadores internos de su inversión y demanda.

\section{Cambios en la estructura productiva}

La estructura productiva configurada en los países en desarrollo es determinada por las decisiones de inversión tomadas por las empresas transnacionales ubicadas en éstos, como por las políticas industriales instrumentadas en los diversos países. Nos dicen Hiratuka y Sarti (2011) que "la reestructuración global... fue condicionada por las estrategias de internacionalización y de gestión de la cadena de producción y de valor de las grandes empresas transnacionales". La dinámica industrial de los países pasa a estar determinada por el comportamiento del comercio mundial, como por el papel que desempeñan sus empresas en el encadenamiento internacional del cual forman parte, y de su capacidad para hacer frente a la competencia frente a los productos del exterior. El valor agregado nacional que incorpora su producción, es importante, ya que ello determina el efecto multiplicador interno, y por lo tanto, la dinámica del sector manufacturero.

Casi todas las ramas industriales presentan altos niveles de internacionalización, reflejado ello en sus altos coeficientes de importación, como en sus coeficientes de exportación, lo que las lleva a depender del financiamiento externo para su crecimiento. Tal proceso es comandado en mayor medida por empresas extranjeras.

Los países latinoamericanos han procedido en mayor o menor medida a la apertura comercial, bajo el principio de que la competencia contribuiría a la modernización del aparato productivo, lo que permitiría ampliar mercados, y configurar condiciones de crecimiento superiores a la estrategia de sustitución de importaciones, y que se mejoraría la posición de la balanza de comercio exterior para cubrir el pago del servicio de la deuda externa. Con la liberalización comercial, se dejó de lado la política industrial que impulsó el desarrollo manufacturero en todos los países, que fue la política proteccionista, y se redujo por lo tanto la capacidad del gobierno para incidir sobre las características de la dinámica manufacturera.

La inversión extranjera que se ha dirigido a nuestras economías, ha sido mayoritariamente inversión de cartera, y la IED ha sido en su mayoría para 
adquirir empresas ya existentes, tanto públicas, como privadas, o porque están integradas a cadenas productivas y vienen a aprovechar las ventajas comparativas que tiene la región, pero no desarrollan tecnología, y la que traen no irradia al conjunto del sector. No se han instrumentado en nuestros países políticas para condicionar la entrada de dichas empresas, y no se les ha colocado reglas de comportamiento a favor de lo nacional. Las empresas extranjeras que operan para el mercado interno, han desplazado a las nacionales, que además de configurar estructuras oligopólicas, y trabajan con altos coeficientes importados, por lo que su dinámica no irradia al conjunto del sector manufacturero, y presionan sobre su balanza de comercio exterior.

La liberalización económica ha ido acompañada de políticas macroeconómicas de estabilidad cambiaria, exigidas por el sector financiero, por lo que han predominado políticas monetaria y crediticia restrictivas, así como disciplina fiscal, encaminadas a asegurar la estabilidad del tipo de cambio, que ha configurado monedas apreciadas. Todo ello es la antítesis de una política industrial, ya que merma las condiciones de acumulación del sector manufacturero. Éste requiere de contextos de protección, de dinámica de la demanda, bajas tasas de interés, disponibilidad crediticia, tipos de cambio competitivos, y políticas de subsidios, entre otras, que dejaron de predominar.

Las empresas dejan de contar con los apoyos y medidas que deben emanar de una política industrial, necesarias para sortear la apertura económica. Las políticas macroeconómicas predominantes restringen los márgenes de maniobra del gobierno en la actividad económica, pues deja de tener política monetaria, crediticia, cambiaria y fiscal para tener política industrial, e impulsar el desarrollo tecnológico, mejorar competitividad para alcanzar una dinámica económica más sostenida, con menos presiones sobre el sector externo, y menos dependiente de las variables externas.

Las empresas dejan de contar con mercados internos dinámicos, con créditos preferenciales a bajas tasas de interés, con subsidios, y exenciones tributarias, lo que merma sus condiciones de acumulación, y además no cuenta (la mayoría de ellas) con acceso a los mercados de capital que apoyen el financiamiento de su inversión para modernizar su planta productiva, para mejorar productividad y competitividad. Han quedado en desventaja en el contexto de la globalización, por lo que ha llevado a que las importaciones manufactureras crezcan más que las exportaciones, originando rompimiento de cadenas productivas, con la consecuente des-industrialización de los países, y mayores presiones sobre el déficit de comercio exterior manufacturero, lo cual frena la dinámica económica, y disminuye el empleo formal de sus economías. 


\section{La financierización de las economías}

Las políticas predominantes configuran mejores opciones de inversión en el sector financiero; así que los flujos de inversión se canalizan a éste sector, a costa de relegar la inversión en el sector manufacturero, por lo que se tiene menos posibilidad de mejorar sus niveles de productividad y competitividad para hacer frente a importaciones, y asegurar su permanencia y desarrollo en el mercado.

Ante los desafíos que coloca la globalización, los gobiernos latinoamericanos han apostado más a favor del sector financiero, para recibir inversión de cartera, tanto al mercado de capitales, como de dinero, y de divisas, para financiar su déficit de cuenta corriente, y mantener su presencia en el proceso de globalización, en vez de crear condiciones macroeconómicas para impulsar el sector manufacturero, y reducir su dependencia de los flujos de capital.

Ello ha llevado a que el sector financiero haya repuntado significativamente, y en cambio la participación del sector manufacturero disminuya su participación en el PIB tanto de los países desarrollados, como la mayoría de los países en desarrollo (véase el caso de México, cuadro 1). El sector servicios incrementa su participación en el PIB, como en la generación de empleo, que son de menor calidad y remuneración que los ofrecidos por el sector manufacturero.

Se ha dado una reestructuración industrial, donde han desaparecido ramas e industrias no competitivas, sin ser sustituidas por otras que mantengan la dinámica industrial y de empleo en el sector, y se ha reducido la participación del sector manufacturero en el piB total, así como la participación relativa y absoluta del empleo manufacturero.

\section{Cuadro | \\ México. PIB manufacturero y financiero como porcentaje del PIB total}

\begin{tabular}{|c|c|c|}
\hline Periodo/Año & PIB manufacturero (\%) & PIB financiero (\%) \\
\hline $1970-1979$ & 22.80 & 9.60 \\
\hline $1980-1989$ & 21.40 & 9.80 \\
\hline $1990-1999$ & 19.20 & 15.90 \\
\hline
\end{tabular}

Fuente: elaboración propia con base en INEGI, BIE y cifras históricas, 2013. 


\section{Des-industrialización mundial}

Se han dado grandes cambios en la estructura productiva mundial en las últimas tres décadas, tanto en su estructura interna, como en el reparto geográfico, ya que la industria manufacturera se volcó hacia Asia, sobre todo a China, y hay una creciente des-industrialización en los países desarrollados, como en los países latinoamericanos. Asimismo, países que antes eran desarrollados, viven ahora problemas que los llevan más a las posiciones de los países subdesarrollados.

De ser el PIB manufacturero 22\% del PIB mundial en 1980, en 2011 pasó a representar $16 \%$, y a pesar de ello, las manufacturas representan $70 \%$ del comercio mundial (Manyica et al., 2012). La mayor reducción de dicha participación se da en los países avanzados, con la consecuente disminución del empleo en el sector manufacturero. La mayor caída se explica por el traslado de las ramas industriales con procesos productivos intensivos en mano de obra a otros países. Las manufacturas vienen creciendo en los países en desarrollo, y disminuyendo en los países avanzados.

En 1980 dentro de los 10 países que encabezan el top ranks de los mayores productores de manufactura en el mundo, había 8 países desarrollados, más China y Brasil. En el 2010, solo hay 6 países desarrollados, y además de China y Brasil, se suman Corea del Sur e India (véase cuadro 2). De 2000 a 2010, la participación de las economías en desarrollo en el valor agregado manufacturero mundial casi se duplicó, pasando de controlar 21 a 39\% (Manyica et al., 2012); China pasa del $7^{\circ}$ lugar al $2^{\circ}$ y Brasil del $8^{\circ}$ al $6^{\circ}$.

\section{Cuadro 2 \\ Ranking de la participación \\ en la producción manufacturera global}

\begin{tabular}{|c|r|r|r|r|}
\hline País/Año & 1980 & 1990 & 2000 & 2010 \\
\hline China & $7^{\circ}$ & $7^{\circ}$ & $4^{\circ}$ & $2^{\circ}$ \\
\hline India & $15^{\circ}$ & $14^{\circ}$ & $14^{\circ}$ & $10^{\circ}$ \\
\hline Brasil & $8^{\circ}$ & $8^{\circ}$ & $12^{\circ}$ & $6^{\circ}$ \\
\hline Corea del Sur & n.d. & $11^{\circ}$ & $8^{\circ}$ & $7^{\circ}$ \\
\hline México & $11^{\circ}$ & $12^{\circ}$ & $10^{\circ}$ & $12^{\circ}$ \\
\hline
\end{tabular}

Fuente: IHs Global Insight, McKinsey Global Institute Analisys, 2012.

Aquellos países que han aplicado políticas macroeconómicas e industriales a favor del sector manufacturero, para ofrecer condiciones de rentabilidad en dicho sector, para promover flujos de inversión y empresas extranjeras, para 
aprovechar, potenciar y crear las ventajas comparativas y competitivas ofrecidas para incrementar exportaciones, como para desarrollar tecnología, incrementar el valor agregado nacional de las exportaciones, y para crecer en torno al mercado interno, han resultado exitosos.

\section{China}

China abrió su economía en 1979, para instrumentar su estrategia de crecimiento de exportaciones, logrando una participación creciente en el mercado internacional. Permitió la apertura comercial para facilitar las importaciones ligadas a exportaciones, pero no para el mercado interno, el cual ha sido protegido (Barbosa, 2005). China siguió las políticas de Corea del Sur, como de Japón, de apoyar y constituir grandes empresas con economías de escala, con capacidad competitiva en el mercado internacional (Singh, 2007), y ha realizado fuertes inversiones en ciencia y tecnología, como en infraestructura, y en el desarrollo de capital humano.

Las empresas públicas configuraron grandes conglomerados para potenciar el financiamiento para su desarrollo tecnológico, y tener economías de escala y mejorar su competitividad frente a empresas transnacionales en el mercado internacional (Barbosa, 2005), China descansa en gran parte en la asistencia pública a las nuevas industrias. Los estímulos a las empresas exportadoras, han contribuido a penetrar los mercados competitivos mundiales (Rodrik, 2008).

China se abrió a la IED, pero sujeta a rígidas regulaciones y controles. China e India, han negociado en mejores términos con las empresas transnacionales, imponiéndoles condiciones a favor del desarrollo industrial nacional, tales como desarrollo de tecnología y la transferencia de ésta a la industria nacional (comandada por empresas públicas). Se ha dado una asociación de empresas transnacionales con empresas públicas para contar con tecnología y mejorar su productividad, e impulsar el crecimiento de sus exportaciones, y se ha exigido alto valor agregado nacional en las exportaciones, lo que le ha permitido apuntalar su esfera productiva, y su productividad, así como el crecimiento de diversas regiones.

China ha sido la economía de más rápido crecimiento en el mundo en las últimas tres décadas. Su crecimiento contrasta con la desaceleración de las economías avanzadas, como resultado del traslado de ramas manufactureras desde éstos países hacia las economías en desarrollo, donde China e India han sido de las más exitosas en aprovechar las transformaciones de la industria manufacturera a nivel mundial. Ello ha permitido el incremento de la participación 
del sector manufacturero en tales países. El hecho que la dinámica manufacturera se haya volcado hacia China, como a otros países asiáticos y a India, ha generado procesos de desindustrialización en los países desarrollados, lo cual se da conjuntamente con el llamado proceso de financierización presente en estas economías, como consecuencia de que este sector pasó a ofrecer mejores alternativas de inversión, propiciando prácticas especulativas que han terminado configurando crisis financieras y económicas recurrentes y cada vez más profundas, que están desacelerando la economía mundial e incrementando el desempleo, y la desigualdad del ingreso. La posición competitiva de China le ha permitido tener superávit de comercio exterior, y alto crecimiento económico, a costa de que el resto de los países tenga déficit, y menor crecimiento, tal es el caso de Estados Unidos, Europa, América Latina, entre otros.

La creciente participación de la manufactura en China e India, no contrarresta la desindustrialización que se da a nivel mundial. La participación manufacturera en el PIB de China en 2010, era 33\%, en Corea del Sur 28\%, Japón 20\%, Alemania 19\%, México 17\%, Italia 15\%, Rusia 14\%, Brasil 13\%, India 13\%, España 12\%, Estados Unidos 12\% Canadá 11\%, Francia y RU 10\% (Manyica et al., 2012).

El empleo manufacturero en China e India de 2000 a 2008 aumentó casi 30\%, y en las economías avanzadas disminuyó 19\% (Manyica, et al., 2012).

El control del movimiento de capitales, le ha permitido evitar prácticas especulativas en su mercado financiero, y la apreciación del tipo de cambio, el cual es controlado en función de sus objetivos de competitividad y de crecimiento de sus exportaciones, como para avanzar en la sustitución de importaciones. No le deja al mercado la determinación de su tipo de cambio.

El control del movimiento de capitales, y el predominio de un tipo de cambio competitivo, le permiten tener política fiscal, monetaria y crediticia que impulsan su mercado interno, como la disponibilidad crediticia a favor de su permanente modernización y reestructuración de su sector manufacturero. Su superávit de comercio exterior, el tipo de cambio competitivo con que ha trabajado, y sus grandes reservas internacionales, le permiten trabajar con baja tasa de interés, y flexibilidad crediticia para apuntalar la inversión industrial. Así en el 2012 la inversión en relación al PIB en China fue de 47.8\%, y en la India de 36\% (datos del FMI).

Ante el desarrollo espectacular que está teniendo la industria manufacturera de China, enfrenta problemas de escasez de mano de obra calificada (no obstante la fuerte inversión en capital humano que se realiza), lo cual presiona al alza los salarios. Como respuesta está moviendo empresas a regímenes de menores costos, como Bangladesh, Camboya, Indonesia, Vietnam (Manyica, et al., 2012). 
El ingreso per cápita en China para más de mil millones de habitantes se ha duplicado en 12 años (Manyica, et al., 2012). Ello, conjuntamente con el incremento de salarios que se viene dando últimamente, le ha permitido reorientar la producción hacia el mercado interno, para contrarrestar la caída de la dinámica de sus exportaciones a raíz de la crisis de 2008 .

China representa un mercado muy grande, que está aumentando su poder adquisitivo, por lo que continúan los grandes flujos de IED, no solo para producir para exportar, sino también para el mercado interno. China recibe más de 60\% de la IED de los países de la OECD (Singh, 2007).

China ha venido incrementando su IED hacia el resto del mundo. Después de haber recibido (y estar recibiendo) grandes flujos de IED, ahora ellos están realizando inversiones fuera de su país, sobre todo para allegarse de materias primas, como para aprovechar costos laborales menores a los de ellos. Señala Dussel (2012a) que la IED que China realiza tiene aprobación de sus instituciones, y la mayoría es propiedad del Estado, y 99\% de ésta se ha destinado a materias primas y energía, y América Latina es la segunda más grande receptora de tales inversiones. China se ha constituido en una de las principales economías que realizan IED desde la crisis de 2007-2008.

En el cuadro 3 podemos observar como los flujos de inversión hacia China se han estabilizado a raíz de la crisis de 2008, y en cambio, las que ellos realizan en otros países se han incrementado a partir de dicha fecha.

\section{Cuadro 3 \\ China: Flujos de IED}

(cifras en millones de dólares)

\begin{tabular}{|c|c|c|}
\hline Año & IED a China & IED de China \\
\hline 1990 & 3487 & 830 \\
\hline 1995 & 37521 & 2000 \\
\hline 2000 & 40715 & 916 \\
\hline 2005 & 72406 & 12261 \\
\hline 2006 & 72715 & 21160 \\
\hline 2008 & 83521 & 22469 \\
\hline 2009 & 108312 & 52150 \\
\hline
\end{tabular}

Fuente: UnCTAD, 2012. Tomado de Dussel (2012a). 
Hay una creciente participación de los productos manufactureros de China en toda América Latina, manifestándose ello en déficit de comercio exterior manufactureros, como en rompimientos de cadenas productivas y des-industrialización de nuestros países. La presencia de los productos de China en los mercados internacionales, ha actuado en detrimento de la presencia de las exportaciones de los productos latinoamericanos en dichos mercados (Hiratuka y Sarti, 2010).

\section{India}

India, aunque no crece tanto como China, ha visto triplicado su ingreso per capita en los últimos 25 años (Singh, 2007). India se caracteriza por tener grandes instituciones, y su política de planeación quinquenal, que le permite mecanismos de control de los agentes económicos para el cumplimento de las metas fijadas. El gobierno ha impulsado la innovación tecnológica, como la educación en la formación de capital humano, para el impulso de la productividad, y competitividad de su producción.

En los años ochenta procedió a la desregulación de la inversión interna, lo que permitió que ésta incrementara la producción, tanto para el mercado interno, como externo, pero no se liberalizó el sector externo (Singh, 2007).

La liberalización comercial y de la inversión extranjera se dio a inicios de los años noventa, pero la economía ya venía creciendo desde los años ochenta evidenciando que su crecimiento no puede ser atribuido al liberalismo (Singh, 2008).

A pesar que en los años noventa India redujo drásticamente sus aranceles a la importación, éstos continúan siendo altos en términos relativos a otros países. India es de las economías más protegidas, con altos impuestos a las importaciones, y con barreras no tarifarias al comercio, las cuales se han reducido con su ingreso a la Organización Mundial de Comercio (Singh, 2008). A pesar de la liberalización comercial, siguió la política industrial, que logró un crecimiento industrial sostenido. El crecimiento económico de India se ha sostenido más en el mercado interno, que en las exportaciones (Singh, 2007).

Al igual que China, ha controlado el movimiento de capitales, para evitar prácticas especulativas, como distorsión de precios relativos que puedan actuar a favor de lo financiero y en detrimento de lo productivo. Sin embargo, ha ido liberalizando en forma gradual (Singh, 2008) y en el caso de su cuenta de capitales de balanza de pagos, se regula su comportamiento. Al tener control y regulación del movimiento de capitales, puede trabajar con bajas tasas de in- 
terés, y tipo de cambio competitivo, y no como en América Latina, donde al predominar la libre movilidad de capitales, las economías tienen que trabajar con alta tasa de interés, disciplina fiscal y estabilidad del tipo de cambio (que termina apreciando la moneda), para evitar prácticas especulativas de salidas de capital, lo cual impide tener política macroeconómica que acompañe a una política industrial. Las autoridades de India señalan que la tasa de interés y el tipo de cambio son determinadas por el mercado, pero que ellos "intervienen sólo para mantener alineadas las tasas y evitar agudas fluctuaciones" (Deparment of Industrial Policy and Promotion, 2012).

La banca está regulada y controlada, y es mayoritariamente del gobierno, por lo que actúa a favor de otorgar créditos al sector productivo, y dicho control evita prácticas especulativas. Cabe resaltar que los países en desarrollo que han sido exitosos en su desarrollo industrial y en el crecimiento de exportaciones, como Corea del Sur, China e India, se caracterizan porque la banca pertenecía (o sigue perteneciendo en mayor o menor medida) al gobierno, lo que permite tener garantizado el financiamiento para apuntalar el desarrollo productivo y tecnológico de sus economías.

Los subsidios crediticios y fiscales que recibían las empresas, eran condicionados a metas de productividad, de exportación y de mayor valor agregado nacional, y el que no cumplía era sancionado, a diferencia de las políticas industriales instrumentadas en América Latina, que se otorgaron sin pedir nada a cambio, por lo que las políticas proteccionistas configuraron ganancias monopólicas que no se traducían en mayor inversión para modernizar la planta productiva, e incrementar el coeficiente de exportación.

Este país, como algunos del sudeste asiático, ha prohibido la participación de la inversión extranjera en sus sectores estratégicos. La participación de las empresas extranjeras está controlada, según la rama en que operan. En unas tienen que asociarse con empresas nacionales, y en otras ramas pueden participar con 100\%. Impone a los contratistas que ganan contratos superiores a los 60 millones de dólares, a gastar entre 30 y $50 \%$ del precio de venta de bienes y servicios en las industrias del país, o hacer inversiones directas en ciencia y tecnología (Manyica et al., 2012: 82).

Las pequeñas empresas cuentan con un Ministerio de Industria de Pequeña Escala que las favorece a través de subsidios, asistencia técnica, así como líneas crediticias preferenciales, y existe una línea de productos manufactureros que solo pueden ser elaborados por pequeñas empresas (Velasco, 2005).

La agricultura pasó del período 1950-1992, de ser 43.1\% del PIB, a ser 16.0\% en 2009-2010. Y la industria pasó en dicho período de 22 a 26\% (De- 
parment of Industrial Policy and Promotion, 2012). La manufacturera (que está dentro del sector industrial) es 16\% del pib, y el Departamento de Política Industrial de dicho país se ha trazado como objetivo incrementar su participación hasta 20\% en 2016, y 25\% en 2022 (Deparment of Industrial Policy and Promotion, 2012).

En la India los servicios han venido creciendo más que la producción manufacturera (Singh, 2007). Su motor de crecimiento lo constituye el sector de información y comunicación tecnológica.

China e India, así como muchos países del sudeste asiático, han contado con políticas macroeconómicas flexibles traducido ello en políticas monetarias, crediticias y fiscales expansionistas, que impulsan el crecimiento del mercado interno, y otorgan disponibilidad crediticia a bajo costo, así como con exenciones tributarias y subsidios, y han predominado tipos de cambios competitivos que contribuyen a mejorar su competitividad y a incrementar exportaciones, redituando todo ello en fuerte desarrollo manufacturero, como en superávit de su balanza de comercio exterior (Torija-Zane, 2012). De 2000 a la fecha, Estados Unidos, y Japón han apreciado su moneda 20\%, mientras China ha devaluado la suya 16\% (Manyica et al., 2012: 99).

La estrategia de industrialización seguida por China e India, ha configurado las bases reales de un crecimiento virtuoso, caracterizado por su fuerte desarrollo de la capacidad productiva, el crecimiento de la productividad, y los superávit de comercio exterior, situación presente en pocos países desarrollados (Japón y Alemania, los más significativos), lo que les ha permitido altas tasas de crecimiento de su PIB, como mejoras significativas del ingreso per cápita, tal como se observa en el cuadro 4, situación ya no presente en los países desarrollados.

\section{Cuadro 4}

\section{China e India: PIB per capita}

\begin{tabular}{|c|c|c|}
\hline \multicolumn{3}{|c|}{ Dólares } \\
\hline Año & China & India \\
\hline 2000 & 946 & 465 \\
\hline 2005 & 1726 & 729 \\
\hline 2011 & 5414 & 1389 \\
\hline
\end{tabular}

Fuente: International Monetary Fund, World Economic Outlook Database, enero de 2013. 


\section{México}

Con el impulso a los tratados de libre comercio, la disminución de aranceles a las importaciones, la disciplina fiscal y la apreciación de la moneda, el gobierno mexicano dejó de tener política industrial. Se procedió a la apertura comercial desde mediados de los años ochenta bajo el principio de que el libre comercio es el que debe determinar la reestructuración de la industria manufacturera, y su inserción en el mercado internacional. El gobierno mexicano, como la mayoría del resto de América Latina dejó de tener presencia directa para incidir en los rumbos y características que debería tener la dinámica manufacturera. Le dieron dicha tarea al mercado. Señala Rodrik (2008) que "la mayoría de los países latinoamericanos renunciaron a la política industrial, como parte de la reorientación de su estrategia económica".

La reestructuración y diseminación de procesos productivos que se ha dado por la apertura comercial y por el desempeño de las empresas transnacionales, determinan en gran medida la inserción que cada país pasa a tener en el proceso de globalización, en función de las ventajas comparativas que ofrecen los países. Ello configura las características que asume la estructura productiva de los países, así como en su dinámica económica.

Las empresas nacionales no cuentan con los niveles tecnológicos, ni con los contactos comerciales para formar parte del engranaje del comercio internacional. El crecimiento de las exportaciones está íntimamente relacionado a la IED. Las empresas ubicadas en México que participan en dicho proceso, son las 'maquiladoras', que son empresas extranjeras que trabajan con altos coeficientes de importación, y bajo valor agregado nacional. Las ventajas comparativas que ofrece el país a las empresas transnacionales, son la baratura de la mano de obra (véase cuadro 5), así como del precio de ciertos recursos derivados del petróleo, y además está la ventaja de localización, por ser vecino del principal mercado del mundo. 


\begin{tabular}{|c|c|}
\hline \multicolumn{2}{|c}{ Cuadro 5 } \\
\begin{tabular}{|c|c|} 
Salario mínimo como como Poder de Paridad \\
Adquisitivo, países seleccionados (dólares)
\end{tabular} \\
\hline País & Salario mínimo en Ppp\$, año 2010 \\
\hline Brasil & 286 \\
\hline China & 173 \\
\hline India & 121 \\
\hline México & 170 \\
\hline Rusia & 223 \\
\hline Sudáfrica & 390 \\
\hline Fuente: International Labour Organization, Global Wage Report, enero de 2013.
\end{tabular}

México se ha especializado en la etapa de montaje de la cadena de producción, la cual se caracteriza por procesos productivos intensivos en mano de obra. Tales empresas no invierten en ciencia y tecnología internamente, y no pagan impuestos. Las exportaciones manufactureras son $80 \%$ del total exportado en el país. En el período 1993-2010, 72.1\% de las exportaciones mexicanas dependieron del programa de importaciones temporales para su exportación (Dussel, 2012b). De ahí las altas importaciones, el alto coeficiente importado de las exportaciones manufactureras, y el bajo efecto de derrame interno de tales exportaciones, explican el hecho de que el crecimiento de exportaciones no vaya acompañado de un crecimiento del PIB manufacturero, ni del PIB nacional, evidenciando que a partir del 2000, tampoco ha habido mercado interno que contrarreste el poco arrastre de dichas exportaciones (véase cuadro 6).

\section{Cuadro 6}

\section{México: Crecimiento porcentual de exportaciones} manufactureras $v s$ PIB manufacturero

\begin{tabular}{|c|c|c|}
\hline Año & PIB manufacturero & Exportaciones manufactureras \\
\hline $1995-2000$ & 7.8 & 16.1 \\
\hline $2008-2009$ & -9.9 & -17.8 \\
\hline $2000-2011$ & 1.6 & 6.1 \\
\hline $\begin{array}{l}\text { Fuente: elaboración propia con base en datos del Centro de Estudios de las Finanzas Públicas (CEFP) } \\
\text { y el Banco de México, Indicadores Económicos y Financieros, 2013. }\end{array}$
\end{tabular}


La industria manufacturera de México está íntimamente relacionada a las exportaciones, y a la dinámica manufacturera de Estados Unidos, dada la alta integración con que operan ambas industrias, pero al tener un alto componente importado, las exportaciones como la producción nacional (véase cuadro 7), se configura un bajo crecimiento de la industria manufacturera nacional.

\section{Cuadro 7}

\section{México: Coeficientes de importación*} por ramas industriales, $2000-2010$

\begin{tabular}{|l|r|r|r|}
\hline \multicolumn{1}{|c|}{ Año } & 2000 & 2005 & 2010 \\
\hline \multicolumn{1}{|c|}{ Total } & 118.5 & 135.6 & 149.9 \\
\hline I. Productos alimenticios, bebidas y tabaco & 14.1 & 20.2 & 22.1 \\
\hline II. Textiles, prendas de vestir e industria del cuero & 58.1 & 72.9 & 65.2 \\
\hline III. Industria de la madera y productos de la madera & 42.4 & 83.4 & 74.0 \\
\hline IV. Productos de papel, imprentas y editoriales & 122.0 & 122.7 & 116.8 \\
\hline V. Sustancias químicas, plástico y hule** & 126.8 & 153.0 & 186.5 \\
\hline VI. Productos de minerales no metálicos & 19.2 & 22.9 & 22.6 \\
\hline VII. Industrias metálicas básicas & 172.2 & 135.6 & 143.4 \\
\hline VIII. Productos metálicos, maquinaria y equipo & 209.2 & 260.9 & 279.6 \\
\hline IX. Otras industrias manufactureras & 280.9 & 211.7 & 280.0 \\
\hline
\end{tabular}

* Es la relación Importaciones sobre el PIB. Se utilizó PIB corriente en base a la metodología del INEGI 1993; se usó el Tipo de Cambio Fix promedio mensual para sacar el promedio anual.

** La rama original es Sustancias químicas, derivados del petróleo, productos de caucho y plástico. Se utilizó únicamente la industria química, caucho y plástico puesto que los derivados del petróleo siguen una dinámica diferente al resto de las ramas manufactureras.

Fuente: BIE, 2013.

El sector empresarial ha sido marginado de la disponibilidad crediticia. La banca gana a través de otorgar crédito al consumo de bienes importados. Los créditos a las empresas son mínimos debido a que no tienen asegurado el reembolso del crédito, dada su baja dinámica de acumulación (véase cuadro 8). 


\section{Cuadro 8}

México: Crédito otorgado por la banca comercial por sectores

\begin{tabular}{|c|c|c|c|c|}
\hline & 1994 & 1997 & 2000 & 2011 \\
\hline РIB & 100 & 100 & 100 & 100 \\
\hline Crédito total & 40.4 & 30.4 & 17.5 & 19.2 \\
\hline \multicolumn{5}{|l|}{ Sector privado del país } \\
\hline I. Empresas y personas físicas & 36.7 & 27.9 & 12.9 & 15.6 \\
\hline a) Sector industrial & 10.4 & 7.7 & 3.4 & 4.0 \\
\hline
\end{tabular}

Fuente: Banco de México, 2013.

Los tratados de libre comercio han logrado que las compras gubernamentales se liciten con los países miembros y que se dé trato similar a las empresas extranjeras, como a las empresas nacionales. El problema es que al ser mayor la productividad de las empresas extranjeras, éstas terminan ofreciendo mejores precios y se adjudican dichas licitaciones, por lo que las compras gubernamentales dejan de operar como política a favor de las empresas nacionales, quedando sujetas a su débil posición competitiva en el contexto de apertura comercial, disminución de aranceles y apreciación del tipo de cambio.

\section{Balanza de comercio exterior en México}

La participación de las exportaciones de México en el mercado estadounidense, se han mantenido en el período 2000-2011 (véase cuadro 9), explicado ello a la posición competitiva que ofrecen los bajos salarios de México, como las ventajas de localización, y el hecho que la apreciación cambiaria, les abarata a las empresas transnacionales los insumos que importan de China y del resto de Asia, lo que mejora su competitividad, y ganancias, y tal paridad no afecta sus exportaciones, pues se dirigen a su país de origen, y las transacciones intraempresas, son en su moneda. Quien pierde, son los productores nacionales que son desplazados por las importaciones, así como el país en su conjunto, dado que le sale muy caro promover entrada de capitales para mantener la moneda apreciada. 


\section{Cuadro 9}

Estados Unidos: principales lugares de origen de las importaciones (estructura porcentual)

\begin{tabular}{|l|c|c|c|}
\hline \multicolumn{1}{|c|}{ País } & 2000 & 2005 & 2011 \\
\hline Canadá & 18.5 & 16.8 & 14.1 \\
\hline China & 8.6 & 15.0 & 18.4 \\
\hline Japón & 12.0 & 8.2 & 5.9 \\
\hline México & 10.9 & 10.0 & 11.7 \\
\hline Unión Europea & 18.7 & 18.5 & 16.6 \\
\hline Fuente: elaboración propia en base a datos de UnCTADSTAT, enero de 2013.
\end{tabular}

En el cuadro 10 podemos observar que las exportaciones que México viene realizando desde 2005 a 2011. Las más dinámicas son las dirigidas a China y a Brasil. En el primero de los casos debido al gran dinamismo de dicha economía, que ha venido demandando, sobre todo, materias primas y petróleo. En el caso de las exportaciones a Brasil, se debe a que con la crisis de 2008-2009 México devaluó más su moneda, que Brasil, lo cual aunado al diferencial de salarios mínimos (véase cuadro 5), ha actuado a favor de la competitividad de la producción nacional, en relación a la de Brasil, permitiendo a México pasar de una situación deficitaria con tal país, a una de superávit de comercio exterior, véase cuadro 11.

\section{Cuadro 10}

México: Exportaciones totales a países seleccionados, Tasa de crecimiento promedio anual, 2005-2011

\begin{tabular}{|l|c|}
\hline \multicolumn{1}{|c|}{ Total } & 8.5 \\
\hline Estados Unidos & 6.9 \\
\hline Canadá & 16.7 \\
\hline Brasil & 32.8 \\
\hline Unión Europea & 12.9 \\
\hline China & 31.8 \\
\hline Fuente: Banco de México, Indicadores económicos y financieros, febrero de 2013.
\end{tabular}




\section{Cuadro II \\ México: Saldo de la Balanza Comercial por países (Millones de dólares)}

\begin{tabular}{|c|r|r|r|r|r|r|r|}
\hline Año & $\begin{array}{c}\text { Estados } \\
\text { Unidos }\end{array}$ & \multicolumn{1}{|c|}{ Brasil } & $\begin{array}{c}\text { Unión } \\
\text { Europea }\end{array}$ & $\begin{array}{c}\text { Federación } \\
\text { Rusa }\end{array}$ & China & India & \multicolumn{1}{c|}{$\begin{array}{c}\text { Resto } \\
\text { de Asia }\end{array}$} \\
\hline 2000 & 19865 & -1286 & -9586 & -327 & -2676 & -229 & -15437 \\
\hline 2005 & 65016 & -4324 & -16838 & -534 & -16561 & -398 & -32315 \\
\hline 2011 & 100075 & 329 & -18639 & -678 & -46284 & -594 & -46280 \\
\hline
\end{tabular}

En lo referente a las importaciones realizadas por México, se observa una drástica caída de las que provienen de Estados Unidos, ya que pasaron de ser 73.1\% del total en el 2000, a 49.7\% en 2010. En cambio la participación de las importaciones provenientes de China aumentaron de 1.65 a $14.89 \%$ en el mismo período. Las de Asia, sin China, pasaron de 9.97 a 15.64\% (véase cuadro 12).

\section{Cuadro I2}

México: Importaciones de países seleccionados (Porcentaje del total de importaciones)

\begin{tabular}{|c|c|c|c|c|}
\hline Año & Estados Unidos & Asia & China & Asia Sin China \\
\hline 1993 & 69.29 & 11.28 & 0.59 & 10.69 \\
\hline 2000 & 73.1 & 11.62 & 1.65 & 9.97 \\
\hline 2011 & 49.7 & 30.53 & 14.89 & 15.64 \\
\hline
\end{tabular}

Fuente: Banco de México, Indicadores económicos y financieros, 2013.

Las importaciones provenientes de China se han incrementado $30.15 \%$ promedio anual de 2000 al 2011, y las importaciones provenientes de Estados Unidos solo lo hicieron $2.88 \%$ (véase cuadro 13). Esos diferenciales de tasas de crecimiento explican el cambio de la estructura de importaciones por países del cuadro 12, como el gran déficit de comercio exterior que se tiene con China (cuadro 11).

\section{Cuadro I3}

México: Importaciones de países seleccionados, 2000-2011, (tasa de crecimiento del periodo)

\begin{tabular}{|c|c|c|c|}
\hline Estados Unidos & Unión Europea & China & Asia sin China \\
\hline 2.88 & 8.50 & 30.15 & 11.01 \\
\hline
\end{tabular}


Las ventajas comparativas han resultado en desventajas, pues el valor agregado nacional de las empresas extranjeras establecidas en el país ha sido mínimo, y la política de apertura comercial y disminución de aranceles que se ha establecido para que operen en el país, ha llevado a que se importe todo tipo de productos, por lo que hay quiebre de cadenas productivas, lo que acentúa la des-industrialización del país, y frena la actividad económica.

El déficit de comercio exterior ha llevado a la economía a depender de la entrada de capitales para financiar dicho déficit y mantener la estabilidad del tipo de cambio. Ello obliga establecer políticas económicas que garanticen las condiciones de estabilidad y rentabilidad necesarias para asegurar los flujos de capital, por lo que predominan políticas monetaria y fiscal restrictivas, esto dificulta la instrumentación de una política industrial que apuntale a dicho sector.

Los cambios ocurridos en la estructura productiva manufacturera mexicana, han ocurrido por el rompimiento de cadenas productivas derivados de los efectos del gran crecimiento de importaciones que propician la apertura comercial, y la apreciación cambiaria, como por el ingreso de las empresas externas que vienen en busca de aprovechar ventajas comparativas dentro de la red de encadenamientos de producción y comercio en que se insertan tales empresas. De hecho, los flujos de IED han sido mucho menores a los de China y lo que recibe Brasil (cuadro 14) evidenciando que no se cuenta con tantas ventajas comparativas, ni mercado interno atractivo como en ellos, y además no han impactado en la dinámica manufacturera, ni en la generación de empleo.

\section{Cuadro |4}

Inversión Extranjera Directa, países seleccionados

(cifras en millones de dólares)

\begin{tabular}{|c|c|c|c|c|}
\hline Año & China & Brasil & India & México \\
\hline 2000 & 40714.80 & 32779.20 & 3588.00 & 18110.00 \\
\hline 2005 & 72406.00 & 15066.30 & 7621.80 & 24407.20 \\
\hline 2011 & 123985.00 & 66660.10 & 31554.00 & 19554.40 \\
\hline
\end{tabular}

Fuente: Statistics UNCTAD, 2013.

En el cuadro 15 podemos observar cómo en el año 2000 el empleo manufacturero representaba $19.5 \%$ del empleo total en el país, y dicha participación pasó a ser de $15.3 \%$ en el 2011. 


\section{Cuadro 15}

México. Empleo manufacturero

como porcentaje del total

\begin{tabular}{|c|c|c|c|}
\hline Año & Empleo total & Manufacturero & Manufacturero \% \\
\hline 2000 & 38410024 & 7507475 & 19.55 \\
\hline 2005 & 41880780 & 6918433 & 16.52 \\
\hline 2011 & 45361833 & 6947000 & 15.31 \\
\hline
\end{tabular}

Fuente: INEGI, Banco de Información Económica, 2013.

\section{México y las reformas estructurales}

Desde hace tres décadas se han impulsado las llamadas reformas estructurales que han llevado a la liberalización económica, a la autonomía del banco central, a la disciplina fiscal, así como a la privatización y extranjerización de los sectores estratégicos. Tales políticas están encaminadas a achicar la participación del Estado en la economía y ampliar la esfera de influencia del capital privado en la economía, bajo el precepto de que ello se traducirá en mayores flujos de inversión y tecnología que apuntalen tales sectores, y reduzcan el precios de los insumos, bienes y servicios ofrecidos por ellos, para así mejorar la competitividad, para atraer más inversión al sector manufacturero para incrementar exportaciones, y así mejorar la posición de la balanza de comercio exterior, y apuntalar la dinámica de la economía. El problema es que ya se tiene años con dichas reformas estructurales, y los resultados no han sido de mayor eficiencia, productividad y competitividad, sino que han implicado cambios patrimoniales que incrementan la concentración de la riqueza y las desigualdades de ingreso. La economía tiene menos condiciones endógenas de acumulación, y ha pasado a depender en forma creciente del comportamiento de las variables externas, y de la entrada de capitales.

Recientemente fue aprobada una reforma laboral, donde permite realizar contrataciones por hora, por periodos, y reduce prestaciones laborales, encaminada a disminuir el costo laboral para mejorar competitividad, en la perspectiva de incrementar exportaciones. México aprovecha el alza de salarios en China, para ofrecer menores salarios, para estimular entrada de empresas internacionales con procesos productivos intensivos en mano de obra, y así incrementar las exportaciones y expandir el sector manufacturero.

Ante la inexistencia de una política industrial que impulse la inversión, la modernización del aparato productivo, la productividad y competitividad, proceden a reducir salarios, pensando que ello alcanzará los objetivos busca- 
dos. La disminución de salarios y prestaciones laborales se vuelve una herramienta competitiva, al no poder el gobierno devaluar la moneda, ni flexibilizar su política fiscal para otorgar subsidios y apoyos al desarrollo tecnológico y a la innovación, y al no poder otorgar créditos baratos al sector privado para estimular la inversión productiva. Muchos países están siguiendo la misma política salarial, por lo que no se mejora competitividad alguna, y terminan sacrificando más el crecimiento del mercado interno. Se sigue apostando al crecimiento hacia fuera, en un contexto donde el mercado internacional tiende a permanecer estancado por mucho tiempo, y donde algunos países están ya instrumentando políticas proteccionistas a favor de su industria y del empleo.

Los bajos salarios existentes, conjuntamente con el resto de las políticas macroeconómicas de 'estabilidad', mantienen un mercado interno contraído, que contribuye el bajo crecimiento manufacturero, y de la economía, ya que no hay motor alguno de crecimiento.

\section{Los desafíos para América Latina ante el escenario de la desaceleración de las economías avanzadas, y del comercio internacional}

La crisis de los países desarrollados ha impactado más a las economías que dependen en gran medida de las variables externas, tanto de exportaciones, como del flujo de capitales. Ha habido un impacto diferencial en función del tipo de productos exportados, siendo los menos afectados aquellos países que exportan commodities (alimentos, materias primas y minerales), a diferencia de los que exportan manufactura, como es el caso de México, que en 2009 las exportaciones manufactureras cayeron $17.8 \%$ (cuadro 6), y el PIB nacional cayó 6.2\%, más que cualquier otra economía de América Latina.

Las economías latinoamericanas que trabajan con plantas productivas pequeñas, sin grandes economías a escala, y baja productividad, no cuentan con los niveles de competitividad requeridos en el mercado internacional, por lo que no pueden participar en éste, y además su producción ha sido desplazada por importaciones, por lo que ven frenado su crecimiento, e incrementadas sus presiones en su balanza de comercio exterior. El haber dejado al libre mercado la determinación de la dinámica manufacturera, ha representado un alto costo, reflejado ello en menos dinámica manufacturera, y del empleo formal, como en presiones sobre el sector externo, y menor dinámica económica.

La desaceleración del mercado internacional ha recrudecido la competencia en dichos mercados, y coloca en desventaja a aquellas economías que no 
muestran desarrollo de productividad, y que trabajan con tipos de cambios apreciados. Éstas ven frenado el crecimiento de sus exportaciones, como su dinámica económica, y se mantienen las presiones sobre el déficit de comercio exterior, lo que recrudece sus problemas de insolvencia, y agrava la inestabilidad de su sector bancario. Ello frena las decisiones de inversión, y está limitando los márgenes de maniobra de la política económica en los gobiernos.

Tal contexto hace más difícil proseguir con la estrategia de crecimiento de exportaciones manufactureras. Además, las políticas macroeconómicas de estabilidad predominantes, dificultan el manejo soberano y flexible de la política económica, para que responda a las necesidades de apuntalar la innovación tecnológica, como otorgar créditos preferenciales a la esfera productiva, y para trabajar con un tipo de cambio competitivo, para que la producción nacional pueda ser competitiva en el mercado internacional, como ante importaciones en el mercado interno. Ello coloca a muchas economías latinoamericanas en una posición de incapacidad para mantener su presencia de sus exportaciones manufactureras en el mercado internacional. La presencia de las exportaciones manufactureras en el comercio mundial se ha reducido ante su falta de competividad frente a China y otros países. En 2000 fueron 4.14\% del total de las exportaciones manufactureras mundiales, y en 2011 fueron de 3.53\% (datos de la UnCTAD, 2013). Además, al tener estos bienes alta elasticidad de ingreso, cae su dinámica cuando se reduce el crecimiento de nuestro principal socio comercial, y no se vislumbran perspectivas de que se supere pronto la crisis de los países desarrollados que está ya impactando a las economías en desarrollo. Los resultados han sido: fuertes rezagos y desequilibrios productivos, des-industrialización, altas tasas de desempleo y presiones crecientes sobre la balanza de comercio exterior manufacturera. Las políticas macroeconómicas de 'estabilidad' que le acompañan, distorsionan el uso y distribución de los recursos, lo que atenta sobre la reestructuración industrial manufacturera que es necesaria para la dinámica económica, y la generación de empleo bien remunerado. Se evidencia una vez más que el mercado por sí solo no configura condiciones de crecimiento sostenido.

El escenario de generalización de la recesión a nivel mundial, conjuntamente con la volatilidad del precio de los commodities, y los problemas de inestabilidad bancaria en los países europeos, que mantienen latente las presiones sobre el mercado de capitales, y de divisas, configuran un contexto de alta incertidumbre en las economías.

Los países, para reducir su vulnerabilidad en torno al comportamiento de la economía internacional, tienen que volcarse a la sustitución de importacio- 
nes para potenciar su crecimiento manufacturero. Los gobiernos tienen que encarar los problemas de des-industrialización, de desaceleración de la actividad económica, de creciente informalidad de las economías, de las presiones sobre la balanza de comercio exterior, y la vulnerabilidad externa en que se ha caído, así como las grandes desigualdades de ingreso, y la creciente pobreza.

Se tiene que retomar el manejo soberano de la política económica e impulsar cambios radicales en el comportamiento de la economía, para poder atender las demandas democráticas de las grandes mayorías de la población, y frenar la extranjerización creciente de nuestras economías.

\section{Retomar el desarrollo manufacturero en torno al mercado interno, como motor del crecimiento}

Se requiere una participación activa del gobierno en la economía, a través de políticas fiscales, comerciales (de protección de mercado), y crediticias, para que la asignación de recursos e inversión actúe a favor del sector manufacturero, el cual es crucial para el impulso de una dinámica económica menos vulnerable, dado el gran valor agregado y desarrollo tecnológico que puede generar, así como por su efecto multiplicador hacia otros sectores de la economía, como para disminuir las presiones sobre la balanza de comercio exterior, y así apuntalar la participación del sector manufacturero en la economía nacional. Dicho sector ofrece mejor estructura salarial, y una dinámica más endógena y auto-sustentada. Para ello se tiene que apoyar a las ramas industriales para que tengan capacidad de hacer frente a la competencia de las importaciones, como para que incrementen su valor agregado nacional para asegurar mayor irradiación interna, y mayor generación de empleo. Señala Ha-Joon Chang (2006) que "todos los países han usado medidas intervencionistas cuando era necesario".

Ante la dificultad de poder dinamizar al sector manufacturero a través de exportaciones (tanto por la desaceleración de la actividad económica por la que atraviesan los países desarrollados, sino también por el bajo valor agregado nacional que las caracteriza), obliga a los países latinoamericanos a colocar el crecimiento del mercado interno como alternativa de desarrollo, para así satisfacer las demandas de empleo y crecimiento, por lo que tendrán que retomar el manejo de la política económica, a favor de la esfera productiva. Ello demanda significativos cambios de la política comercial, cambiaria, fiscal, crediticia, así como mejorar la negociación del Estado frente a las empresas transnacionales. Se debe revisar la apertura indiscriminada, como los bajos 
aranceles existentes, y trabajar con un tipo de cambio competitivo para no colocar en desventaja a la producción nacional frente a importaciones, y así favorecer a la producción, como para reducir el déficit de comercio exterior. La política fiscal es imprescindible para el otorgamiento de subsidios a la producción manufacturera, como para el impulso al desarrollo tecnológico, y a la formación de capital humano, que acompañe el desarrollo manufacturero. Es importante un Estado Nación fuerte que anteponga el interés nacional frente a las empresas internacionales para que impulsen el desarrollo tecnológico internamente, e incrementen el valor agregado de su producción con productos nacionales, en beneficio de la dinámica manufacturera, como de la balanza de comercio exterior.

La falta de opciones de inversión rentable en la esfera productiva que ocasiona la crisis, así como el predominio de políticas macroeconómicas de estabilidad cambiaria, dificultan a empresas y gobiernos realizar inversiones y políticas industriales para impulsar el desarrollo tecnológico, mejorar competitividad, recuperar cadenas productivas, aumentar el valor agregado nacional de la producción como la participación de la producción manufacturera y del empleo manufacturero.

\section{Condiciones para un desarrollo industrial y de política hacia dicho sector}

Frente al escenario de recesión mundial, la política económica tiene que potenciar el crecimiento del mercado interno, para que éste sea el motor del crecimiento. Ello requiere de expansión del gasto público, como políticas de distribución del ingreso. Se tiene que revisar la apertura comercial para evitar filtraciones de demanda hacia importaciones, como impulsar el desarrollo tecnológico y la capacidad productiva para satisfacer la mayor demanda.

Para que la inversión privada se canalice al sector manufacturero, éste tiene que ofrecer condiciones de rentabilidad y crecimiento, lo cual tiene que asegurar la política económica, tanto la de nivel macro, como la política industrial. Una política industrial tiene que incidir en aquellos elementos que aseguren niveles de rentabilidad en dicho sector para que fluya la inversión, y las ganancias se reinviertan en el mismo. Por lo tanto tiene que incidir en el desarrollo tecnológico, en los costos de los insumos productivos, del transporte, y del financiamiento, como en los niveles de la calidad de la mano de obra; así como contemplar subsidios, el crecimiento de la demanda, así como localización del mercado. Señala Manyica et al. (2012) que los "factores fun- 
damentales que son importantes a la industria manufacturera: acceso a bajo costo o mano de obra altamente calificada; proximidad a la demanda; transporte efectivo e infraestructura; disponibilidad de insumos como recursos naturales o energía no cara; proximidad a centros de innovación".

Mientras el sector financiero ofrezca mejores opciones de ganancia que el sector manufacturero, éste continuará rezagado, e incapaz de modernizarse para encarar la competencia de que es objeto en el contexto de liberalización económica. Se tiene que regular al sector financiero para frenar sus prácticas especulativas, y las distorsiones de ganancia, y para que proporcione financiamiento para la inversión de maquinaria y equipo, para el desarrollo de ciencia y tecnología. Si en países como China e India hay políticas a favor de lo productivo, es porque ellos tienen controlado a su sector financiero.

Además, se tiene que regular el movimiento de mercancías, y revisar la política comercial y cambiaria para evitar competencias desleales que actúan en detrimento de los niveles de rentabilidad de la esfera productiva nacional. Toda esta tarea no es fácil. Para tener una política macroeconómica a favor de lo productivo, éste tiene que demandarlo. Tiene que tener la fuerza suficiente para que la política económica responda a sus intereses.

Las políticas instrumentadas por el gobierno tienen que estar condicionadas a resultados de productividad, de mayor encadenamiento productivo, de sustitución de importaciones, de aumento del coeficiente de exportaciones, y sancionar a aquellas que al recibir los estímulos no cumplan con las metas propuestas.

\section{El diagnóstico es necesario para tener política industrial}

Se requiere el diagnóstico de la estructura industrial manufacturera. Estudiar las características que está asumiendo la industria manufacturera, y las reestructuraciones que se han venido manifestando a nivel mundial y nacional. Analizar qué ramas industriales participan en las redes de comercio y en las cadenas de producción internacionales, y el impacto de ello sobre el resto de la industria y el empleo.

El diseño de política industrial tiene que evaluar qué industrias y empresas tienen capacidad para mejorar sus economías de escala, y productividad, y sus niveles competitivos para participar en el comercio mundial, y hacer frente a la competencia de importaciones, y ver cuáles pueden readecuarse para crecer en torno al mercado interno. 
La política industrial a impulsar en nuestros países tiene que contemplar una integración regional, que potencie los procesos productivos donde tenemos ventajas comparativas, competitivas y de localización, en función de nuestros recursos naturales, como de habilidades adquiridas, y de especialización, y formación de recursos humanos que se han desarrollado, para que el comercio interregional que se alcance, genere efectos multiplicadores al interior, para impulsar nuestra dinámica manufacturera y económica, y reduzca nuestros déficit comerciales manufactureros. Es más fácil lograr acuerdos de integración y cooperación regionales y bilaterales entre países del área latinoamericana, que los predominantes entre el Norte y el Sur, donde los desarrollados imponen las reglas del juego a su favor.

La política industrial de subsidios, exenciones tributarias, facilidades crediticias, y de revisión de aranceles, entre otras medidas, por sí sola no resultará efectiva, si no es acompañada de una política que regule al sector financiero (para evitar distorsiones en la estructura de ganancia que afecte al sector manufacturero), como de un tipo de cambio competitivo que configure precios relativos a favor de la producción nacional, y por lo tanto mejores ganancias en ésta. Es imprescindible la regulación del sector bancario-financiero para evitar distorsiones de niveles de ganancia y de precios relativos que actúan en detrimento de los flujos de inversión hacia el sector manufacturero. Se debe priorizar la disponibilidad de créditos hacia la esfera manufacturera para que incremente su inversión y logre los niveles de innovación tecnológica necesarios para mejorar su competitividad, e incrementar el valor agregado nacional, e impulsar efectos multiplicadores internos, y reducciones del déficit de comercio exterior. Nos dice Julio Gomes (2011) que "sin incremento de productividad, y de política que apoye al sector privado en los campos cambiario y de reformas importantes en la economía, ni una buena política industrial será suficiente para cambiar de dirección el proceso que está llevando a una creciente pérdida de posición a la producción brasileña en el exterior y en el mercado interno".

Una política industrial requiere de política macroeconómica (monetaria, cambiaria y fiscal), comercial y crediticia a favor de lo productivo. Es decir, se requiere de política monetaria, y fiscal flexible, que dinamice el mercado interno y asegure así la realización de la producción, que mejore y amplíe la infraestructura, flexibilice y abarate el crédito, así como un tipo de cambio competitivo que mejore la competitividad de la producción nacional.

La flexibilización de la política macroeconómica es indispensable para tener política industrial, pues ésta requiere de bajas tasas de interés, de dispo- 
Economía Informa núm. 384 enero - febrero • 2014

nibilidad crediticia, de política fiscal que otorgue subsidios e incremente la demanda, así como tipo de cambio competitivo, todo lo cual es crucial para impulsar a la esfera productiva y lograr condiciones de crecimiento de largo plazo. La política industrial debe coordinar acciones de los diferentes ministerios e instituciones gubernamentales, conjuntamente con los productores involucrados a fin de eficientar y potenciar las medidas instrumentadas.

\section{Bibliografía}

Barbosa, C. (2005), "Reformas economicas na China", en Revista Economia Política Internacional: Análise Estratégica núm. 5, abr-jun.

Deparment of Industrial Policy and Promotion (2012), "Strategic Plan for the Department of Industrial Policy and Promotion", Ministry of Commerce and Industry, Government of India.

Dussel, E. (2011), "La Manufactura en México: Condiciones y propuestas para el corto, mediano y largo plazo", en Nueva política de industrialización, vol. 7 de Análisis Estratégico para el Desarrollo, de J.L. Calva, Juan Pablos Editor, México.

Dussel, E. (2012a), “Chinese FDI in Latin America: Does Ownership Matter?” en Working Group on Development and Environment in the Americas, Discussion Paper núm. 33, nov, y en www.dusselpeters.com.mx

Dussel, E. (2012b), "Retos para una política de competitividad en México", en www.dusselpeters.com.mx

Gomes, J. (2011), “Alcance e Lacunas da nova Política Industrial” en Texto para Discussao, No. 196, Universidad de Campinas -IE/UniCAmp-, Out.

Ha-Joon Chang (2006), "The Market, The State and Institutions of Economic Development", en Rethinking development economics, Editado por Ha Joon Chang, Anthem Press.

Hiratuka, C. y Sarti, F. (2010), "Indústria mundial: Mudancas e tendencias recentes", en Texto para Discussao, núm. 186, Universidad de Campinas -IE/UnICAMP-, Dezembro.

Kosacoff, B. y Ramos, A. (1999), “El debate sobre política industrial”, en Revista de la CEPAL, núm. 68, agosto.

Manyica, J., et al. (2012) "Manufacturing the future: The next era of global growth and innovation", McKinsey Global Institute-McKinsey Operations Practice, November.

Rodrik, D. (2008), “Normalizing Industrial Policy”, World Bank, Commission on Growth and Development, Issue 3 of Working paper. 
Singh, A. (2007), "Globalisation, Industrial Revolutions in India and China and Labour Markets in Advanced Countries: Implications for National and International Economic Policy”, Policy Integration Department-international, Labour Office, Working Paper núm. 81.

Singh, A. (2008), "The Past, Present and Future of Industrial Policy in India: Adapting to the Changing Domestic and Internacional Environment", Centre for Business Research, University of Cambridge, Working Paper núm. 376.

Torija-Zane, E. (2012), "Desarrollo industrial y política macroeconómica de los dragones asiáticos: 1950-2010", CEPAL y Banco Central de Argentina, Documentos de proyectos, núm. 60, Junio.

unCTAD, (2013), Data and Statistics.

Velasco, S. (2005), "Reformas Economicas na Índia: Discurso e Processo", en Revista Economia Política Internacional: Análise Estratégica, núm. 7, Out-Dez. 